\title{
Antiviral effects of ascorbic and dehydroascorbic acids in vitro
}

\author{
AYAMI FURUYA ${ }^{1,2}$, MISAO UOZAKI ${ }^{1}$, HISASHI YAMASAKI ${ }^{1}$, \\ TSUTOMU ARAKAWA ${ }^{3}$, MIKIO ARITA ${ }^{2}$ and A. HAJIME KOYAMA ${ }^{1}$ \\ ${ }^{1}$ Division of Virology, Department of Cellular and Molecular Medicine, Wakayama Medical University \\ Graduate School of Medicine; ${ }^{2}$ School of Health and Nursing Science, Wakayama Medical University, \\ Wakayama 641-8509, Japan; ${ }^{3}$ Alliance Protein Laboratories, Thousand Oaks, CA 91360, USA
}

Received April 22, 2008; Accepted June 18, 2008

DOI: $10.3892 /$ ijmm_00000053

\begin{abstract}
In the present study, ascorbic acid weakly inhibited the multiplication of viruses of three different families: herpes simplex virus type 1 (HSV-1), influenza virus type A and poliovirus type 1 . Dehydroascorbic acid, an oxidized form of ascorbic acid and hence without reducing ability, showed much stronger antiviral activity than ascorbic acid, indicating that the antiviral activity of ascorbic acid is due to factors other than an antioxidant mechanism. Moreover, addition of $1 \mathrm{mM} \mathrm{Fe}{ }^{3+}$, which oxidizes ascorbic acid to dehydroascorbic acid and also enhances the formation of hydroxyl radicals by ascorbic acid in the culture media, strongly enhanced the antiviral activity of ascorbic acid to a level significantly stronger than that of dehydroascorbic acid. Although both ascorbic acid and dehydroascorbic acid showed some cytotoxicity, the degree of cytotoxicity of the former was 10-fold higher than the latter, suggesting that the observed antiviral activity of ascorbic acid with and without ferric ion is, at least in part, a secondary result of the cytotoxic effect of the reagent, most likely due to the free radicals. However, the possibility that oxidation of ascorbic acid also contributed to the antiviral effects of ascorbic acid exists, in particular in the presence of ferric ion, since dehydroascorbic acid exhibited a very strong antiviral activity. Characterization of the mode of antiviral action of dehydroascorbic acid revealed that the addition of the reagent even at $11 \mathrm{~h}$ post infection almost completely inhibited the formation of progeny infectious virus in the infected cells, indicating that the reagent inhibits HSV-1 multiplication probably at the assembly process of progeny virus particles after the completion of viral DNA replication.
\end{abstract}

Correspondence to: Dr A. Hajime Koyama, Division of Virology, Department of Cellular and Molecular Medicine, Wakayama Medical University Graduate School of Medicine, 811-1 Kimiidera, Wakayama 641-8509, Japan

E-mail:koyama@wakayama-med.ac.jp

Key words: ascorbic acid, dehydroascorbic acid, herpes simplex virus type 1 , influenza virus, antiviral

\section{Introduction}

We previously studied the antiviral activities of various natural products and its components (1-4). Previous characterization of an antiviral activity of n-alkyl esters of gallic acid revealed that octyl gallate inhibits the multiplication of a variety of DNA and RNA viruses $(1,2)$. These gallate derivatives, including octyl gallate, have been well characterized for their pharmacological functions (5), and some of them are currently being used as antioxidant food additives or as quasi drugs in Europe and Japan. Considering the antioxidant property of gallate derivatives, the observed antiviral activity of octyl gallate may be due to its antioxidant activity. To test this possibility, we examined the effect of ascorbic acid, a strong reducing agent, on the multiplication of a variety of DNA and RNA viruses.

Viral infections often lead to oxidative stress to the infected cells and, therefore, certain redox-active substances are expected to suppress oxidative stress and work as antivirals or drugs improving inflammatory symptoms. Among these substances, the protective effect of ascorbic acid has been assumed due to i) its powerful scavenging and antioxidative property and ii) its accumulation in millimoles per liter concentration in neutrophils, lymphocytes and monocytes $(6,7)$. There are many reports in the literature regarding the antiviral effect of ascorbic acid, however, these studies are mostly based on clinical trials or in vivo animal models and not under the defined conditions in vitro ( 8 and refs. therein). The results obtained from these studies must be influenced by inflammatory and immune responses, which makes it difficult to evaluate ascorbic acid as an antiviral agent at the cellular level. In this study, we characterized the direct antiviral action of ascorbic acid in vitro under the defined conditions.

\section{Materials and methods}

Cells and viruses. MDCK, HEp-2 and Vero cells were grown in Eagle's minimum essential medium (MEM) containing 5\% fetal bovine serum. Herpes simplex virus type 1 strain $F$ (HSV-1), influenza virus A/Aichi $\left(\mathrm{H}_{3} \mathrm{~N}_{2}\right)$ and poliovirus type 1 Sabin vaccine strain (PV-1) were used throughout the experiments. The viruses were propagated in Vero cells (for HSV-1 and PV-1) in MEM supplemented with $0.5 \%$ fetal 


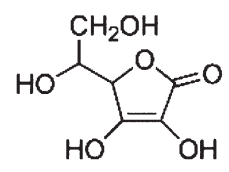

(a)

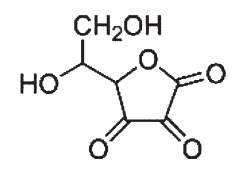

(b)
Figure 1. Structure of ascorbic acid (a) and dehydroascorbic acid (b).

bovine serum or in MDCK cells (for influenza virus) in MEM supplemented with $0.1 \%$ bovine serum albumin (BSA) and acetylated trypsin $(4 \mu \mathrm{g} / \mathrm{ml})$. The viruses were stored at $-80^{\circ} \mathrm{C}$ until use. The amount of each virus was measured by a plaque assay as described previously (9-11).

Effect of the reagent on the virus yields. Both ascorbic acid and dehydroascorbic acid were obtained from Wako Chemicals. The structures of these reagents are shown in Fig. 1. The reagent solutions $(1.0 \mathrm{M}$ or $100 \mathrm{mM})$ were prepared by dissolving the reagents in hot water, followed by filtration through a Millipore Dimex membrane (pore size $0.22 \mu \mathrm{m}$ ).

Monolayered cells in 35-mm dishes were infected with the virus at an indicated multiplicity of infection (MOI). The infected cells were further incubated at $37^{\circ} \mathrm{C}$ (for HSV-1 and influenza virus) or $35.5^{\circ} \mathrm{C}$ (for PV-1) for the indicated period in the serum-free MEM containing $0.1 \%$ BSA and the indicated concentrations of the reagents. For the experiments with influenza virus, acetylated trypsin $(4 \mu \mathrm{g} / \mathrm{ml})$ was also added to the medium for the proteolytic activation of virus infectivity. At the indicated time, the culture medium was harvested and the amount of total progeny virus in the culture was determined as described previously (9-11).

Determination of cytopathic effects and cell death. Monolayers of HEp-2 cells were incubated at $37^{\circ} \mathrm{C}$ for $24 \mathrm{~h}$ in the serum-free MEM containing $0.1 \% \mathrm{BSA}$ and the indicated concentrations of the reagents. The cytopathic effects (CPE) were determined by a microscopic observation of the cells; approximate amounts of rounded cells on monolayers were estimated using a phase contrast microscope.

To determine the extent of cell death, monolayered cells were trypsinized to obtain a single-cell suspension. After the addition of MEM containing $10 \%$ calf serum to the suspension to neutralize the trypsin and to stabilize the cells, the number of living or dead cells was determined by a dye-exclusion method with trypan blue.

\section{Results and Discussion}

Effect of ascorbic acid on the multiplication of DNA and RNA viruses. It can be expected from its antioxidant property that the antiviral activity of ascorbic acid is not virus-specific. To confirm this, we tested three viruses of completely different types: HSV-1 (Herpesviridae family), influenza virus type A (Orthomyxoviridae family) and PV-1 (Picornaviridae family). Both HSV-1 and influenza virus are large enveloped viruses and need the cell nucleus for virus multiplication, but the former has a double-stranded DNA genome while the latter has a negative-stranded RNA genome $(12,13)$. In

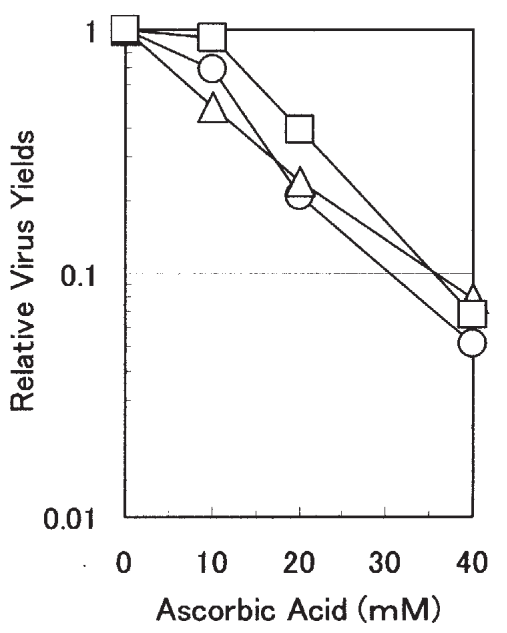

Figure 2. Effect of ascorbic acid on the virus yields. Confluent monolayers of HEp-2 (for HSV-1 and PV-1) or MDCK (for influenza virus) cells were infected with each of these viruses at a MOI of 10 for HSV-1 and 7 for influenza virus or PV-1. The infected cells were incubated for the indicated period in the medium containing varying concentrations of ascorbic acid at $37^{\circ} \mathrm{C}$ for HSV-1 and influenza virus or at $35.5^{\circ} \mathrm{C}$ for PV-1. At the end of infection, the amounts of infectious progeny viruses were determined and were normalized to the virus yield in the absence of the reagent. $\odot$, HSV-1; $\triangle$, influenza virus; $\square, \mathrm{PV}-1$.

contrast to these two viruses, PV-1 is a small non-enveloped virus carrying a positive-stranded RNA as a genome which replicates in the cytoplasm of the infected cells (14).

Fig. 2 shows the effects of ascorbic acid on the relative virus yields of these three viruses, when the cells infected with either of the viruses were incubated in the medium containing various concentrations of the reagent. The multiplication of all three viruses was similarly sensitive to the reagent. The virus yield decreased as the reagent concentration was increased and, in the presence of $30 \mathrm{mM}$ of the reagent, the yields of these viruses were approximately one tenth of those in the absence of the reagent. These results clearly show that ascorbic acid inhibits the multiplication of viruses of widely different structures, i.e., regardless of enveloped or nonenveloped, double-stranded DNA or single-stranded RNA genome, and regardless whether the replication and transcription of the viral genome occur in the nucleus or in the cytoplasm of the infected cells. It is noteworthy that the antiviral activity of the reagent was apparently independent of the type of cells since the multiplication of influenza virus was examined on MDCK cells (derived from canine kidney cells) while that of HSV-1 and PV-1 was on HEp-2 cells (derived from human cervical carcinoma).

Reducing activity vs. oxidizing activity of ascorbic acid. Although ascorbic acid is well-known to be a potent antioxidant and conveys a reducing activity, the reagent stimulates an oxidation reaction in the presence of ferric ion and oxygen; oxidation of ascorbic acid is rapid in the presence of $\mathrm{Fe}^{3+}$ forming dehydroascorbic acid and $\mathrm{Fe}^{++}$, which in the presence of oxygen is rapidly oxidized back to $\mathrm{Fe}^{3+}$ and simultaneously generates hydroxyl radicals. Even a trace amount of ferric ion in the medium can allow ascorbic acid to 


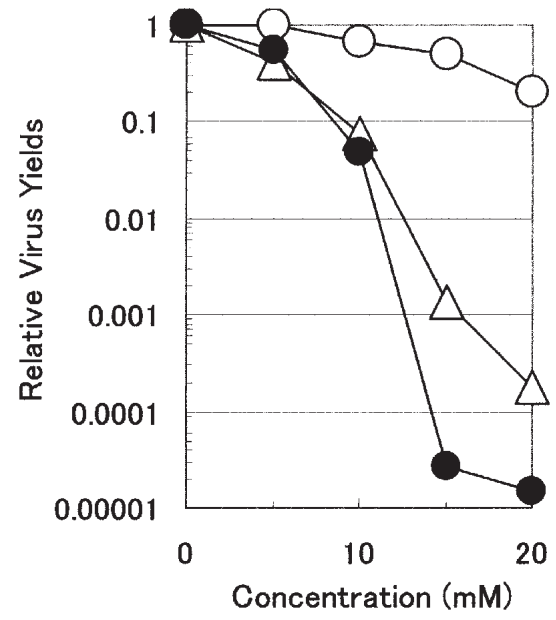

Figure 3. Effect of ascorbic acid or dehydroascorbic acid on HSV-1. Confluent monolayers of HEp-2 cells were infected with HSV-1 at a MOI of 10 . The infected cells were incubated for $16 \mathrm{~h}$ in MEM containing $0.1 \%$ $\mathrm{BSA}$ and varying concentrations of each reagent at $37^{\circ} \mathrm{C}$. At the end of infection, the amounts of total infectious progeny viruses were determined and were normalized to the virus yield in the absence of the reagent. $\odot$, ascorbic acid; $\triangle$, dehydroascorbic acid; $\bullet$, ascorbic acid in the presence of $1.0 \mathrm{mM}$ ferric chloride.

generate hydroxyl radicals that catalyze the oxidation reaction. To examine the possible participation of the oxidation reaction by ascorbic acid in the observed antiviral activity, we measured i) the effects of ascorbic acid on the virus multiplication in the presence of ferric ion and ii) the effects of dehydroascorbic acid on the virus multiplication.

When the effect of ascorbic acid on the yield of HSV-1 was examined in the presence of $1 \mathrm{mM}$ ferric chloride, the reagent showed a much stronger antiviral effect on HSV-1 than in the absence of ferric ions. As shown in Fig. 3, even at $10 \mathrm{mM}$, the reagent in the presence of ferric ion suppressed the virus yield one tenth of that of the control untreated culture while, in the absence of ferric ion, the reagent at $10 \mathrm{mM}$ showed only marginal decrease in the virus yield. There are two possibilities for the augmented antiviral activity of ascorbic acid by ferric ion: i) the enhanced production of free radicals and ii) the formation of dehydroascorbic acid as discussed above. Fig. 3 also shows the effect of dehydroascorbic acid on the yield of HSV-1. Dehydroascorbic acid also markedly decreased the yield with a greater antiviral effect at increasing concentrations, although the degree of the decrease was slightly less than that with ascorbic acid in the presence of ferric ion.

A similar result was obtained for influenza virus using MDCK cells instead of an HSV-1 and HEp-2 cell combination. As shown in Fig. 4, both ascorbic acid in the presence of ferric ion and dehydroascorbic acid showed clearly stronger antiviral activity than ascorbic acid, and the relative degrees of the antiviral effects under these two experimental conditions were similar to those in Fig. 3. The observed antiviral activities of dehydroascorbic acid clearly indicate that its effect is not due to an antioxidant mechanism since this reagent has no reducing potential. It has been shown that dehydroascorbic acid binds to proteins $(15,16)$ and can modify lysine residues to form glycation adducts (17), or more specifically inhibits

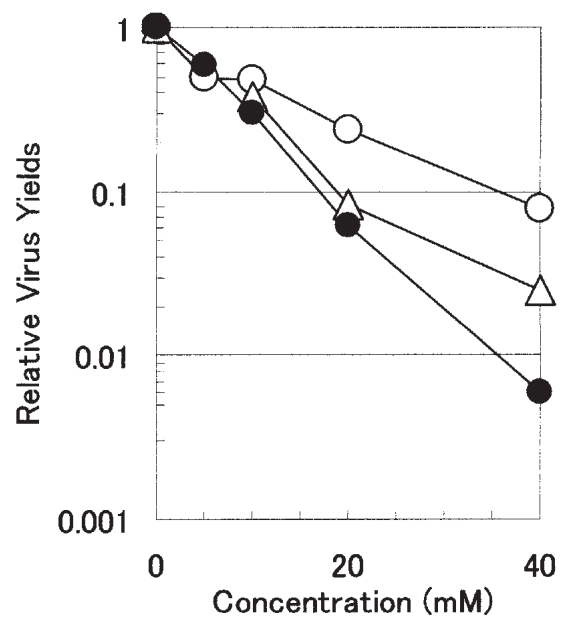

Figure 4. Effect of ascorbic acid or dehydroascorbic acid on influenza virus. Confluent monolayers of MDCK cells were infected with influenza virus at a MOI of 7. The infected cells were incubated at $37^{\circ} \mathrm{C}$ in MEM containing $0.1 \% \mathrm{BSA}, 4 \mu \mathrm{g} / \mathrm{ml}$ of acetylated trypsin and varying concentrations of each reagent at $37^{\circ} \mathrm{C}$. At the end of infection, the amounts of total infectious progeny viruses were determined. $\odot$, ascorbic acid; $\bullet$, dehydroascorbic acid; $\triangle$, ascorbic acid in the presence of $1.0 \mathrm{mM}$ ferric chloride.

certain kinases and enzymes (18-20), although we do not know whether these mechanisms operate in the observed antiviral activity of dehydroascorbic acid at this moment. The observed weak activity of ascorbic acid in the absence of ferric ion and an enhanced effect in the presence of ferric ion may be due to free radicals or dehydroascorbic acid formed, or both In both cases (HSV-1 and influenza virus), the virus yield was less with ascorbic acid together with ferric ion than with dehydroascorbic acid at identical reagent concentrations This suggests a contribution of free radicals to the antiviral activity of ascorbic acid since the radicals cannot be generated from dehydroascorbic acid.

Cytopathic effects of the reagents. During the characterization of the antiviral action of these reagents, we noted that the reagents induced marked CPE (cell rounding and detachment from the dish surface) of the virus-infected cells. Previously we proposed the potential mechanism of antiviral compounds, which can selectively accelerate the death of the virus-infected cells, as the selective acceleration is usually associated with a significant suppression of the progeny virus production $(21,22)$. However, in the case of ascorbic acid and dehydroascorbic acid, the reagents apparently do not selectively accelerate the $\mathrm{CPE}$ in the virus-infected cells (data not shown), although both reagents induced CPE in HEp-2 and MDCK cells after addition to the culture media, independent of the virus infection.

Consistent with these observations of CPE, when the monolayers of HEp-2 cells were incubated in the presence of various concentrations of the reagents for $24 \mathrm{~h}$, cell death was induced in the reagent-treated cells concentrationdependently. As shown in Fig. 5, ascorbic acid induced significant cell death even at $1.6 \mathrm{mM}$ and drastically increased the number of dead cells with increasing concentrations of the reagent. Considering the concentration of ascorbic acid 


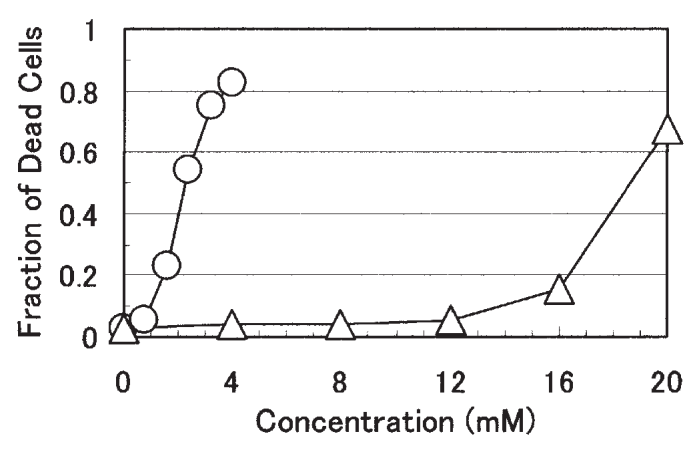

Figure 5. Effect of ascorbic acid or dehydroascorbic acid on cell viability. Confluent monolayers of HEp-2 cells were incubated in MEM containing $0.1 \% \mathrm{BSA}$ and varying concentrations of each reagent at $37^{\circ} \mathrm{C}$. After incubation for $24 \mathrm{~h}$, the treated cells were trypsinized to obtain a single-cell suspension, and the amounts of live and dead cells in each culture were determined by a dye-exclusion test with trypan blue. $\odot$, ascorbic acid; $\triangle$, dehydroascorbic acid.

required to observe the antiviral activity, i.e., higher than $10 \mathrm{mM}$, the observed cytotoxicity of the reagent suggests that the observed reduction in the virus yield is, at least in part, due to the toxic effect of the reagent on the infected cells. This cytotoxicity of the reagent is considered to be the result of hydroxyl radicals generated by the catalytic action of metal ion in the culture medium since, even in the absence of extraneously added ferric ion, a trace amount of this ion exists in the culture media. In contrast to ascorbic acid, the induction of cell death by dehydroascorbic acid occurred at 10 -fold higher concentrations, while its antiviral activity on HSV-1 was much stronger than ascorbic acid. These results suggest that the suppression of virus multiplication by dehydroascorbic acid is unlikely to be due to the side effect on the infected cells, since cell death occurred at reagent concentrations much higher than the concentration sufficient to decrease the virus yield. To note, the direct antiviral activity of ascorbic acid is not due to an antioxidant mechanism, at least in the system examined, rather it is due, at least in part, to the toxic effect of the reagent on the cells.

Dehydroascorbic acid-sensitive step in the HSV-1 multiplication . Previously, we quantitatively characterized the kinetics of the viral DNA replication, the encapsidation of the viral DNA, the envelopment of the nucleocapsids and the formation of infectious progeny virus in HSV-1-infected cells (23) and revealed that viral DNA replication occurs exclusively between $3 \mathrm{~h}$ post infection (p.i.) and $6 \mathrm{~h}$ p.i., and a large amount of nucleocapsids is accumulated in the infected cells when the replication of virus DNA is completed. The formation of infectious progeny virus begins at $5 \mathrm{~h}$ p.i. and the amount of the progeny virus increases with time until approximately $14 \mathrm{~h}$ p.i. To examine the target of the antiviral activity of dehydroascorbic acid in the virus multiplication process, the reagent was added to the infected culture at various times after infection, and the virus yield at the end of virus multiplication was compared to the yield without addition of the reagent. As shown in Fig. 6, the amounts of progeny virus were markedly suppressed even when the infected cells received the reagent at $11 \mathrm{~h}$ p.i. These results

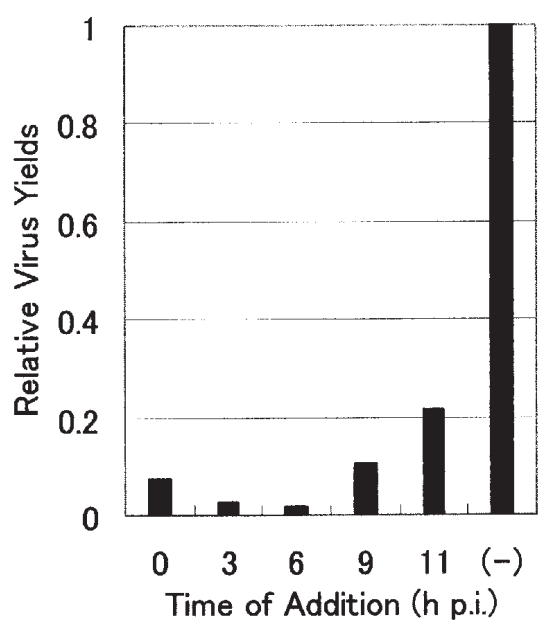

Figure 6. Effect of the time of addition of dehydroascorbic acid on the virus yield. A group of confluent monolayers of HEp-2 cells were infected with HSV-1 at a MOI of 10 and were incubated in MEM containing 0.1\% BSA. At various times after the infection, dehydroascorbic acid was added to the culture medium at the final concentration of $10 \mathrm{mM}$, and then the infected cells were further incubated in the presence of the reagent. The total progeny virus in each culture was harvested at $23 \mathrm{~h}$ p.i., and the amount of virus was determined.

clearly show that the reagent can interfere with the virus multiplication after the completion of the viral DNA replication; the reagent can inhibit the virus multiplication probably at the step of the formation of progeny infectious virus since similar kinetics were observed when the multiplication of HSV-1 was inhibited by ammonium chloride (9) or Brefeldin A (24) at the step of formation of infectious progeny virus after the viral DNA replication and nucleocapsid formation.

In this study, we showed that ascorbic acid inhibits the multiplication of several viruses of widely different structures and replication strategies. Characterization of the mode of action of ascorbic acid and dehydroascorbic acid suggests that either free radical formation or direct binding, or both, is responsible for the antiviral activity of these two reagents. The effect of these reagents on cell viability suggests that the antiviral effect of ascorbic acid is, at least in part, a secondary result of the cytotoxic effect of the reagent. The antiviral effect of dehydroascorbic acid is possibly due to its binding to the virus or molecules involved in viral replication. Characterization of the mode of antiviral activity of dehydroascorbic acid against HSV-1 revealed that the addition of the reagent at $11 \mathrm{~h}$ p.i. can inhibit the formation of progeny virus in the infected cells, suggesting that the reagent affects the HSV-1 multiplication after the completion of viral DNA replication, probably at the stage of maturation, i.e., the assembly of progeny virus particles, although involvement of other step(s) in the multiplication process cannot be excluded.

\section{Acknowledgements}

The authors thank Ms. Kazuko Tsujimoto and Yukiko Katsuyama for their excellent technical assistance and Drs Hideo Iwahashi and Kazuaki Fukushima (Wakayama Medical University) for their helpful discussions. 


\section{References}

1. Uozaki M, Yamasaki H, Katsuyama Y, Higuchi M, Higuchi T and Koyama AH: Antiviral effect of octyl gallate against DNA and RNA viruses. Antiviral Res 73: 85-91, 2007.

2. Yamasaki H, Uozaki M, Katsuyama Y, Utsunomiya H, Arakawa T, Higuchi M, Higuti T and Koyama AH: Antiviral effect of octyl gallate against influenza and other RNA viruses. Int J Mol Med 19: 685-688, 2007.

3. Utsunomiya H, Ichinose M, Uozaki M, Tsujimoto K, Yamasaki H and Koyama AH: Antiviral activities of coffee extracts in vitro. Food Chem Toxicol 46: 1919-1924, 2008.

4. Murayama M, Tujimoto K, Uozaki M, Katsuyama Y, Yamasaki H, Utsunomiya $\mathrm{H}$ and Koyama $\mathrm{AH}$ : Effect of caffeine on the multiplication of DNA and RNA viruses. Mol Med Rep 1: 251-255, 2008

5. Van der Heijden CA, Janssen PJCM and Strik JJTWA: Toxicology of gallates: A review and evaluation. Food Chem Toxicol 24: 1067-1070, 1986.

6. Evans RM, Currie L and Campbell A: The distribution of ascorbic acid between various cellular components of blood, in normal individuals, and its relation to the plasma concentration. Br J Nutr 47: 473-482, 1982.

7. Bergsten P, Amitai G, Kehrl J, Dhariwal KR, Klein HG and Levine M: Millimolar concentrations of ascorbic acid in purified human mononuclear leukocytes. Depletion and reaccumulation. J Biol Chem 265: 2584-2587, 1990.

8. Li W, Maeda N and Beck MA: Vitamin C deficiency increases the lung pathology of influenza virus-infected gulo $^{-/-}$mice. $\mathbf{J}$ Nutr 136: 2611-2616, 2006.

9. Koyama AH and Uchida T: The effect of ammonium chloride on the multiplication of herpes simplex virus type 1 in Vero cells. Virus Res 13: 271-282, 1989.

10. Kurokawa M, Koyama AH, Yasuoka S and Adachi A: Influenza virus overcomes apoptosis by rapid multiplication. Int J Mol Med 3: 527-530, 1999.

11. Koyama AH, Irie H, Ueno F, Ogawa M, Nomoto A and Adachi A: Suppression of apoptotic and necrotic cell death by poliovirus. J Gen Virol 82: 2965-2972, 2001.

12. Roizman B and Knipe DM: Herpes simplex virus and their replication. In: Fields Virology. Fields BN, Knipe DM and Howley PM (eds). 4th edition, Lippincott-Raven, New York, pp2399-2460, 2001.
13. Lamb RA and Kruchikokug RM: Orthomyxoviridae: The viruses and their replication. In: Fields Virology. Fields BN, Knipe DM and Howley PM (eds). 4th edition, LippincottRaven, New York, pp1487-1530, 2001.

14. Racaniello VR: Picornaviridae: The viruses and their replication. In: Fields Virology. Fields BN, Knipe DM and Howley PM (eds). 4th edition, Lippincott-Raven, New York, pp685-722, 2001.

15. Meucci E, Martorana GE, Ursitti A, Miggiano GA, Mordente A and Castelli A: Vitamin C-bovine serum albumin binding behavior. Ital J Biochem 36: 75-81, 1987.

16. Lozinsky E, Novoselsky A, Glaser R, Shames AI, Likhtenshtein GI and Meyerstein D: Effect of ionic strength on the binding of ascorbate to albumin. Biochim Biophys Acta 1571: 239-244, 2002.

17. Slight SH, Feather MS and Ortwerth BJ: Glycation of lens proteins by the oxidation products of ascorbic acid. Biochem Biophys Acta 1038: 367-374, 1990.

18. Fiorani M, De Sanctis R, Scarlatti F, Vallorani L, De Bellis R, Serafini G, Bianchi M and Stocchi V: Dehydroascorbic acid irreversibly inhibits hexokinase activity. Mol Cell Biochem 209: 145-153, 2000.

19. Neault JF, Benkiran A, Malonga $\mathrm{H}$ and Tajmir-Riahl HA: The effects of anions on the solution structure of Na, K-ATPase. J Biomol Struct Dyn 19: 95-102, 2001.

20. Carcamo JM, Pedraza A, Borquez-Ojeda O, Zhang B, Sanchez R and Golde DW: Vitamin $C$ is a kinase inhibitor: dehydroascorbic acid inhibits IkappaBalpha kinase beta. Mol Cell Biol 24: 6645-6652, 2004.

21. Koyama AH, Arakawa $\mathrm{T}$ and Adachi A: Acceleration of virusinduced apoptosis by tumor necrosis factor. FEBS Lett 426: 179-182, 1998.

22. Koyama AH, Fukumori T, Fujita M, Irie $H$ and Adachi A: Physiological significance of apoptosis in animal virus infection. Microbes Infect 2: 1111-1117, 2000.

23. Koyama $\mathrm{AH}$ and Uchida T: Quantitative studies on the maturation process of herpes simplex virus type 1 in Vero cells. Virus Res 10: 281-286, 1988.

24. Koyama $\mathrm{AH}$ and Uchida $\mathrm{T}$ : Inhibition by Brefeldin $\mathrm{A}$ of the envelopment of nucleocapsids in herpes simplex virus type 1infected Vero cells. Arch Virol 135: 305-317, 1994. 